\title{
Seric concentrations of copper, chromium, manganesum, nickel and selenium in aerobic, anaerobic and mixed professional sportsmen
}

\author{
Marcos Maynar', Francisco Llerena², Ignacio Bartolomé ${ }^{1}$, Javier Alves³ ${ }^{3}$ María-Concepción Robles4, \\ Francisco-Javier Grijota ${ }^{3}$ and Diego Muñoz ${ }^{4^{*}}$
}

\begin{abstract}
Background: The aim of the present study was to determine changes in serum concentrations of trace elements Cooper (Cu), Chromiun (Cr), Manganesum (Mn), Nickel (Ni) and Selenium (Se) in high-level sportsmen.

Methods: Eighty professional athletes of different metabolic modalities, were recruited before the start of their training period. Thirty one sedentary participants of the same geographic area constituted the control group. $\mathrm{Cu}, \mathrm{Cr}, \mathrm{Mn}, \mathrm{Ni}$ and Se analysis was performed by Inductively Coupled Plasma Mass Spectrometry (ICP-MS).

Results: Higher concentrations of $\mathrm{Cr}(p<0.001), \mathrm{Mn}(p<0.085)$, and $\mathrm{Ni}(p<0.001)$ were found in sportsmen in comparison to controls, inversely, Se values were lower $(p<0.001)$ among sportsmen. When sportsmen were classified by metabolic modalities, it was found that aerobic-anaerobic group had higher $(p<0.01)$ Cu concentrations than controls and the other sportsmen. The highest $\mathrm{Cr}$ values were found in aerobic participants. For $\mathrm{Mn}$, the major levels were found in aerobic and aerobic-anaerobic groups as well $(p<0.001)$. The lowest Se levels were found among anaerobic sportsmen $(p<0.001)$.
\end{abstract}

Conclusion: This research showed that daily, continuum physical training induced alterations in serum essential minerals concentrations, as well as that these changes can be dependent of the exercise modality practiced.

Keywords: Essential metals, Serum, Metabolism, Exercise, Adaptations

\section{Background}

Essential trace elements such as chromium (Cr), copper $(\mathrm{Cu})$, manganese $(\mathrm{Mn})$, nickel $(\mathrm{Ni})$ and selenium (Se) are needed in small amounts in the human body. Despite of the minuscule organic quantities, all of them are necessary for the maintenance and regulation of many biological functions. $\mathrm{Cr}$ is linked to the carbohydrates metabolism, modifying blood glucose levels and acting as an insulin enhancer. Besides, $\mathrm{Cr}$ is also involved in the lipids metabolism and in the protein anabolism [1-3]. Ni takes part in the tissular regulation of phospholipids, triglycerides, urea,

\footnotetext{
* Correspondence: diegomun@unex.es

${ }^{4}$ Department of Physical Education and Sport, School of Sport Sciences, University of Extremadura, University Avenue, 10003 Cáceres, Spain Full list of author information is available at the end of the article
}

glucose, glycogen and ATP levels $[4,5] . \mathrm{Cu}, \mathrm{Mn}$ and Se are critical elements of the three main cellular antioxidant enzymes, the copper-zinc-superoxide dismutase (Cu-Zn-SOD), the manganese-superoxide dismutase (Mn-SOD) and the glutathione-peroxidase (GSH-Px), respectively. It has been demonstrated that all three enzymes suffer exercise-induced adaptations [6]. Furthermore, lower concentrations of $\mathrm{Cu}, \mathrm{Mn}$ and Se could induce injuries in body functions and physical performance downgrade [7]. It is known that physical activity leads to many metabolic changes in human organism; intense training exercises may increase essential trace elements requirements, either by augmented degradation rates or by increased losses from the body. However, the differences in organic concentrations of these elements of sportsmen in 
comparison to sedentary population have been poorly studied. Furthermore, it has been recently reported that physical training may induce changes in serum concentrations of several biological minerals [8].

The aim of this study was to determine differences in serum $\mathrm{Cr}, \mathrm{Cu}, \mathrm{Mn}, \mathrm{Ni}$ and Se values in sportsmen in comparison to sedentary population as well as to evaluate if different metabolic modalities induced differences in these serum minerals concentrations.

\section{Methods}

\section{Participants}

This research was carried out under the Helsinki Declaration ethic guidelines, updated at the World Medical Assembly in Seoul in 2008, for research with human participants. All the participants were previously informed about the purpose of the study and gave their voluntary signed informed consent.

Eighty male professional athletes and 31 sedentary males participated in the present survey. All of them were living in Cáceres (Spain) and had been living in the same region for, at least, two years. The athletes had trained regularly for the two previous years. All participant completed a nutritional questionnaire about their nutritional habits to ensure they were not taking any vitamins, minerals or other supplementation and to guarantee they all had a similar diet.

The athletes were classified into four groups: athletes group (SPG) (athletes; $n=80$ ) of all the modalities (aerobic + anaerobic + aerobic-anaerobic) with an average age of $20.32 \pm 3.24$ years; aerobic athletes group (AEG) (Aerobic: long distance runners; $n=28$ ) average aged of $21.58 \pm 4.39$ years; anaerobic athletes group (ANEG) (Anaerobic: judo and speed athletes; $n=24$ ) with an average age of $20.11 \pm 2.56$ years; and aero-anaerobic athletes group (AE-ANEG) (Aerobic-anaerobic: professional football players; 28 individuals) with and average age of $22.23 \pm 4.30$. Sedentary students, with an average age of $21.78 \pm 3.52$ years, formed the control group (CG).

The beginning of the survey started at the end of October. At the moment of the beginning all athletes had started their respective training seasons. All SPG participants had been performing high level physical training, at least, two years before the beginning of the survey. AEG training routine consisted of $120 \mathrm{Km} /$ week, performing 3-4 days/week in aerobic conditions or aerobic fartlek and 2-3 days/week of intense series and interval training. The training routine of the ANEG consisted of 5-6 training days/week, performing 3-4 h/ day of specific routines. AE-ANEG participants started their competition in September. All AE-ANEG sportsmen performed an average of 3-4 h/day, 4-5 days/week of mixed physical (aerobic-anaerobic intensities), technical and tactical exercises.

\section{Anthropometric measurements}

The morphological characteristics of the participants were measured in the morning and always at the same time and in identical conditions. Body height was measured to the nearest $0.1 \mathrm{~cm}$ using a wallmounted stadiometer (Seca 220. Hamburg. Germany), and body weight was measured to the nearest $0.01 \mathrm{~kg}$ using calibrated electronic digital scales (Seca 769. Hamburg. Germany) in nude, barefoot conditions. Body fat content was estimated from sum of 4 skinfolds (abdominal, suprailiac, tricipital and subescapularis) and sum of 6 skinfolds (previous skinfolds, thigh and calf skinfolds). The $\Sigma 4$ and $\Sigma 6$ skinfold thicknesses were measured with a Harpenden calliper (Holtain Skinfold Caliper. Crosswell, UK). Measurements were made by the same operator, skilled in kinanthropometry techniques, in accordance with the International Society for the Advancement of Kinanthropometry recommendations. Heart rate and blood pressure were determined using an automatic sphygmomanometer (Omron HEM-780. Osaka. Japan) by a skilled technician, and after a five-minute rest period in supine position.

\section{Physical performance evaluation}

To evaluate the performance variables of the athletes and controls, an exercise test was performed in a treadmill (Powerjoc. Uk), equipped with a gas analyser (Metamax. Cortex Biophysik. Gmbh. Germany) and a Polar pulsometer (Polar. Norway). To ensure a warm-up phase, all participants ran before the test during $15 \mathrm{~min}$ ending at the initial speed of the test. For the test, the participants ran on a treadmill, incrementally in stages, until exhaustion, starting at a speed of $6 \mathrm{~km} \cdot \mathrm{h}-1$ the CG and at $10 \mathrm{~km} \cdot \mathrm{h}-1$ the SPG, increasing the speed at $1 \mathrm{~km} \cdot \mathrm{h}-1$ every $400 \mathrm{~m}$, with a stable slope of $1 \%$, and always within the recommended parameters [9]. The two days before the test, training intensity was reduced, applying regenerative load in order to avoid pre-test fatigue.

The criteria used to determine maximal oxygen uptake $\left(\mathrm{VO}_{2 \max }\right)$ was a stabilisation in oxygen uptake $\left(\mathrm{VO}_{2}\right)$ accompanied of an increment in carbon dioxide $\left(\mathrm{CO}_{2}\right)$ elimination, in respiratory exchange ratio (RER), and ventilatory volume (VE) induced by increments in exercise intensity $(\mathrm{Km} / \mathrm{h})$ in the treadmill. To ensure that physical tests were until exhaustion, athletes should come to the test in recovered conditions (normal basal parameters) and the RER had to exceed 1.

To verify the theoretical differences among sport groups and to ensure that each participant was properly classified in each group, and considering $\mathrm{VO}_{2 \max }$, maximal RER ( RER $\left._{\text {max }}\right)$ was used. The justification of this 
criteria is based in the concept of RER, which defines de ratio between oxygen $\left(\mathrm{O}_{2}\right)$ consumed and carbon dioxide $\left(\mathrm{CO}_{2}\right)$ eliminated. When RER exceeds 1.0 it means that the metabolic production of $\mathrm{CO}_{2}$ overmatches the $\mathrm{O}_{2}$ metabolic utilization, which implies that the exceed in $\mathrm{CO}_{2}$ elimination comes from anaerobic metabolisms. This idea has been demonstrated by Goedecke et al. [10]. These authors demonstrated that RER is highly determined by lactate production. In this sense, anaerobic sportsmen can produce, buffer and tolerate more lactate than aerobic ones [11] which is reflected in higher RER $_{\max }$ values. Furthermore, aerobic sportsmen are highly affected by lactate accumulation, which supposes one of the main muscle fatigue precursors and one of the main performance limiting factors [12]. The inability of aerobic sportsmen to buffer and tolerate lactate is reflected in their $R E R_{\max }$ values, which should be virtually lower than anaerobic sportsmen values.

\section{Nutritional evaluation}

In order to ensure participants were not taking any vitamins, minerals or other supplementations and in order to guarantee they were following a similar diet, all participants completed a dietary questionnaire. The questionnaire consisted in a 3-day daily nutritional record, in two pre-assigned weekdays and in one weekend day. In each day participants indicated, individually, the type, frequency and quantity (in grams) of every food consumed, then the nutritional composition of their diets was evaluated using different food tables and databases [13-15]. Results of this nutritional evaluation are collected in Tables 3 and 4.

\section{Sample collection}

Participants were recruited at 9 am for the extraction of $5 \mathrm{~mL}$ of venous blood from the antecubital vein, using a plastic syringe fitted with a stainless-steel needle. All extractions were carried out in fasting conditions. In order to obtain reliable results, all athletes were advised to rest the two previous days before the tests as well as not to train the morning before the extractions. The blood sample was collected into a metal-free polypropylene tube (previously washed with diluted nitric acid). Later, the blood sample was centrifuged at $2500 \mathrm{rpm}$ for $10 \mathrm{~min}$ at room temperature to isolate the serum. The serum was aliquoted into an Eppendorf tube (previously washed with diluted nitric acid) and conserved at $-80^{\circ}$ $\mathrm{C}$ until the biochemical analysis.

\section{Experimental protocol}

\section{Serum trace elements determination}

$\mathrm{Cr}, \mathrm{Cu}, \mathrm{Mn}, \mathrm{Ni}$ and Se was performed by inductively coupled plasma mass spectrometry (ICP-MS). Decomposition of the organic matrix was performed by heating for $10 \mathrm{~h}$ at $90{ }^{\circ} \mathrm{C}$ after the addition of $0.8 \mathrm{~mL} \mathrm{HNO}_{3}$ and $0.4 \mathrm{~mL} \mathrm{H}_{2} \mathrm{O}_{2}$ to $1 \mathrm{~mL}$ of serum [16]. The samples were then dried at $200{ }^{\circ} \mathrm{C}$ on a hot plate. Sample reconstitution was carried out by adding $0.5 \mathrm{~mL}$ of nitric acid, $10 \mu \mathrm{L}$ of In $(10 \mathrm{mg} \cdot \mathrm{L}-1)$ as internal standard and ultrapure water to complete $10 \mathrm{~mL}$. Reagent blanks, element standards and certified reference material (Seronorm, lot 0511545, Sero AS Billingstand, Norway) were prepared in the same way and used for accuracy testing. Before the analysis, the commercial control materials were diluted according to the recommendation of the manufacturer. Digested solutions were assayed by an ICP-MS Nexion model 300D (PerkinElmer, Inc., Shelton, CT, USA) equipped with a triple quadrupole mass detector in addition to a reaction cell/collision that allows operation in three modes: STD (no reaction gas), KED or kinetic energy discrimination (with helium as the collision gas) and DRC or reaction mode (with ammonia as the reaction gas). Both collision and reaction gases such as argon plasma had a purity of $99.999 \%$ and were supplied by Praxair (Madrid, Spain). Two mass flow controllers regulated gas flows. The frequency generator was free-swinging and worked at $40 \mathrm{Mhz}$. Three replicates were analysed per sample. Quantification was performed by indium (In) as internal standard. The values of the standard materials of each element $(10 \mu \mathrm{g} \cdot \mathrm{L}-1)$ measured for quality controls were in good agreement with intra and inter-assay variation coefficients of less than $5 \%$.

\section{Statistical evaluations}

Statistical analyses were performed with the IBM SPSS Statistic software version 19 for Windows. The results are expressed as $x \pm s$, where $x$ are the mean values and $s$ the standard deviation. A $p$-value of $\mathrm{p} \leq 0.05$ was considered statistically significant.

The normal distribution of the variables was assessed using the Shapiro-Wilks test. Student T test was used to evaluate differences between CG and SPG, and One-way Anova test followed by Bonferroni post hoc test were used to determine differences between CG, AEG, ANEG and AE-ANEG. The differences were evaluated in the anthropometric, cardiorespiratory, nutritional and seric variables.

\section{Results}

Anthropometric and cardiorespiratory characteristics

Table 1 shows data obtained in the anthropometric and cardiorespiratory evaluations from the two groups. It can be observed that SPG had a total body weight and fat values $(\Sigma$ of skinfolds) significantly lower $(p<0.001)$ than the CG. $\mathrm{VO}_{2 \max }$ was significantly higher $(p<0.001)$ in athletes compared to sedentary group. Resting heart rate was lower $(p<0.01)$ in athletes in respect to the 
Table 1 Anthropometric characteristics of control group and athletes

\begin{tabular}{|c|c|c|}
\hline & $\begin{array}{l}C G \\
(n=31)\end{array}$ & $\begin{array}{l}\text { SPG } \\
(n=80)\end{array}$ \\
\hline Height (m) & $1.76 \pm 0.057$ & $1.76 \pm 0.07$ \\
\hline Weight (kg) & $78.21 \pm 12.19$ & $65.31 \pm 7.55^{* * *}$ \\
\hline Age (years) & $21.78 \pm 3.52$ & $20.32 \pm 3.24$ \\
\hline$\sum 4$ skinfolds (mm) & $52.02 \pm 23.77$ & $35.12 \pm 9.29^{* * *}$ \\
\hline$\sum 6$ skinfolds (mm) & $88.82 \pm 34.50$ & $45.85 \pm 16.69^{* * *}$ \\
\hline$V O_{2 M a ́ x}(\mathrm{~mL} \cdot \min -1 \cdot \mathrm{kg}-1)$ & $41.89 \pm 7.50$ & $64.08 \pm 5.27^{* * *}$ \\
\hline$H R_{\text {basal }}($ beat.min-1) & $71.58 \pm 7.38$ & $59.75 \pm 9.66^{*}$ \\
\hline
\end{tabular}

Student test $\left({ }^{*} p<0.05,{ }^{* *} p<0.01 ;{ }^{* * *} p<0.001\right)$ differences between control and sportsmen groups

control group. No differences were found in the age of all participants. As in can be observed in this survey the different groups are well-characterized.

Table 2 shows data about the SPG, separated by metabolic exercise specialty. AEG and ANEG show lower $(p<$ $0.001)$ body weight, followed by AE-ANEG $(p<0.05)$. However, in relation to fat, AEG have the least $(p<0.001)$ values followed by ANEG $(p<0.001)$ and AE-ANEG $(p<$ $0.01)$. In relation to the oxygen update, the AEG have a higher $(p<0.001)$ value followed by ANEG $(p<0.001)$ and AE-ANEG $(p<0.01)$ in respect the CG. For its part, resting heart rate was lower $(p<0.01)$ in AEG followed by AE-ANEG $(p<0.05)$ and ANEG $(p<0.05)$. Furthermore, it was found significant differences in the RER max $_{\text {ax }}$ of AEG and ANEG in comparison to CG, presenting the first group the lowest $(p<0.05)$ values and the second one the highest $(p<0.05)$ results.

\section{Nutritional intake of minerals}

Table 3 collects data about the nutritional intake of all participants. It can be observed in this table that sportsmen presented higher $(p<0.01)$ caloric intake than
Table 3 Nutritional intake of trace elements with essential functions demonstrated: $\mathrm{Cr}, \mathrm{Cu}, \mathrm{Mn}, \mathrm{Ni}$ and Se in control group and sportsmen

\begin{tabular}{lll}
\hline $\begin{array}{l}\text { Elements } \\
\text { (Reference Daily Intake) }\end{array}$ & $\begin{array}{l}\text { CG } \\
(n=31)\end{array}$ & $\begin{array}{l}\text { SPG } \\
(n=80)\end{array}$ \\
\hline Energy $(\mathrm{Kcal} / \mathrm{d})$ & $2243.64 \pm 251.98$ & $2860 \pm 198.31^{* *}$ \\
$\mathrm{Cr}(50-200 \mu \mathrm{g} / \mathrm{d})$ & $95.71 \pm 53.30$ & $125.71 \pm 63.53$ \\
$\mathrm{Cu}(2000-3000 \mu \mathrm{g} / \mathrm{d})$ & $1842.10 \pm 636.21$ & $1715.00 \pm 615.01$ \\
$\mathrm{Mn}(2500-5000 \mu \mathrm{g} / \mathrm{d})$ & $3053.66 \pm 1222.17$ & $3216.80 \pm 1360.18$ \\
$\mathrm{Ni}(50-150 \mu \mathrm{g} / \mathrm{d})$ & $102.25 \pm 15.73$ & $108.66 \pm 16.62$ \\
Se $(50-200 \mu \mathrm{g} / \mathrm{d})$ & $100.82 \pm 18.24$ & $97.31 \pm 19.48$ \\
\hline Student test $(* * p<0.01)$ differences between control and sportsmen groups
\end{tabular}

controls. No significant differences were found among groups in the intake of any mineral.

Table 4 presents data about the nutritional intake of the subjects of the different groups. It can be observed that only AG presented higher $(p<0.001)$ caloric intake than CG.

\section{Serum mineral concentrations}

Table 5 shows serum essential trace minerals data of CG and SPG. It is interesting that in the SPG exist higher basal concentrations of $\mathrm{Cr}, \mathrm{Cu}, \mathrm{Mn}$ and $\mathrm{Ni}$, being statistically significant in the cases of $\mathrm{Cr}, \mathrm{Ni}(p<0,001)$ and Mn $(p<0.05)$. Aversely, basal serum Se concentrations of SPG were lower than CG; being this diminution highly significant $(p<0.001)$.

Table 6 shows the serum concentrations of CG and SPG separated by metabolic modalities. $\mathrm{Cr}$ presents higher $(p<0,001)$ levels in all sport modalities than in CG, being the highest concentration of AEG, followed by AE-ANEG $(p<0.001)$ and ANEG $(p<0.001)$.

In relation to $\mathrm{Cu}$, it can be observed that only $\mathrm{AE}$ and AENG have similar concentrations than CG. Only serum concentrations of $\mathrm{Cu}$ in AE-ANEG participants were

Table 2 Characteristics of control group and sportsmen classified by metabolic modalities

\begin{tabular}{|c|c|c|c|c|}
\hline & $\begin{array}{l}C G \\
(n=31)\end{array}$ & $\begin{array}{l}\text { AEG } \\
(n=28)\end{array}$ & $\begin{array}{l}\text { ANEG } \\
(n=24)\end{array}$ & $\begin{array}{l}\text { AE-ANEG } \\
(n=28)\end{array}$ \\
\hline Height (m) & $1.76 \pm 0.05$ & $1.77 \pm 0.05$ & $1.73 \pm 0.07$ & $1.80 \pm 0.05$ \\
\hline Weight (kg) & $78.21 \pm 12.19$ & $64.95 \pm 7.10^{* * *}$ & $64.91 \pm 8.46^{* * *}$ & $73.78 \pm 6.12^{*+t+m}$ \\
\hline Age (years) & $21.78 \pm 3.52$ & $21.58 \pm 4.39$ & $20.11 \pm 2.56$ & $22.23 \pm 4.30$ \\
\hline$\sum 4$ skinfolds (mm) & $52.02 \pm 23.77$ & $32.56 \pm 8.75^{* * *}$ & $33.66 \pm 9.87^{* * *}$ & $38.25 \pm 10.06^{* * \dagger}$ \\
\hline$\Sigma 6$ skinfolds (mm) & $88.82 \pm 34.50$ & $49.69 \pm 14.84^{* * *}$ & $56.32 \pm 16.65^{* *+\dagger}$ & $59.49 \pm 17.10^{* *+\dagger}$ \\
\hline$V_{2 M a ́ x}\left(\mathrm{~mL} \cdot \mathrm{min}^{-1} \cdot \mathrm{kg}^{-1}\right)$ & $41.89 \pm 7.50$ & $66.17 \pm 8.36^{* * *}$ & $61.23 \pm 3.00^{* * * \dagger}$ & $59.85 \pm 4.53^{* *+十}$ \\
\hline $\mathrm{RER}_{\max }$ & $1.17 \pm 0.10$ & $1.10 \pm 0.08^{*}$ & $1.25 \pm 0.06^{*}$ & $1.15 \pm 0.09$ \\
\hline$H R_{\text {basal }}\left(\right.$ beats $\cdot \min ^{-1}$ ) & $72.58 \pm 7.38$ & $54.90 \pm 10.85^{* *}$ & $62.85 \pm 7.57^{*+\dagger}$ & $57.21 \pm 10.51^{* \bullet}$ \\
\hline HRmax (beats.min ${ }^{-1}$ ) & $184.32 \pm 12.71$ & $173.44 \pm 8.3^{*}$ & $195.10 \pm 8.45^{\bullet}$ & $174.62 \pm 11.68$ \\
\hline
\end{tabular}

Anova and Bonferroni. $\left.{ }^{*} p<0.05 ;{ }^{* *} p<0.01 ; * * p<0.001\right)$ differences between control group and aerobic, anaerobic and aerobic-anaerobic groups; ( $p<0.05$; †† $p<0.01$; †† $p<0.001)$ differences between aerobic group and anaerobic and aerobic-anaerobic groups; $(\square<<0.05 ; \square=p<0.01 ; \square \square \square<0.001)$ differences between anaerobic group and aerobic-anaerobic group 
Table 4 Nutritional intake of trace elements $\mathrm{Cr}, \mathrm{Cu}, \mathrm{Mn}$, Ni and Se of control group and sportsmen separated by metabolic specialties

\begin{tabular}{|c|c|c|c|c|}
\hline \multirow[t]{2}{*}{ Element } & CG & AEG & ANEG & AE-ANEG \\
\hline & $(n=31)$ & $(n=28)$ & $(n=24)$ & $(n=28)$ \\
\hline Energy (Kcal/d) & $2243.64 \pm 251.98$ & $2989.12 \pm 200.22^{* * *}$ & $2215.22 \pm 265.15$ & $2571.13 \pm 211.56$ \\
\hline $\operatorname{Cr}(\mu \mathrm{g} / \mathrm{d})$ & $95.71 \pm 53.30$ & $145.71 \pm 74.13$ & $110.42 \pm 73.10$ & $94.71 \pm 53.30$ \\
\hline $\mathrm{Cu}(\mu \mathrm{g} / \mathrm{d})$ & $1842.10 \pm 636.21$ & $1642.00 \pm 761.01$ & $1874.75 \pm 687.14$ & $1714.23 \pm 742.31$ \\
\hline$M n(\mu g / d)$ & $3053.66 \pm 1222.17$ & $3367.22 \pm 1432.12$ & $3200.24 \pm 1422.21$ & $2998.28 \pm 1547.12$ \\
\hline $\mathrm{Ni}(\mu \mathrm{g} / \mathrm{d})$ & $102.25 \pm 15.73$ & $110.31 \pm 17.44$ & $99.22 \pm 16.93$ & $104.72 \pm 17.33$ \\
\hline $\operatorname{Se}(\mu \mathrm{g} / \mathrm{d})$ & $100.82 \pm 18.24$ & $97.31 \pm 19.48$ & $99.17 \pm 28.15$ & $89.01 \pm 24,11$ \\
\hline
\end{tabular}

Anova and Bonferroni tests. ${ }^{* *} p<0.001$

higher $(p<0,01)$ than CG. In comparison with the other exercise modalities this sportsman, also, has higher $(p<$ $0,01)$ concentration than AEG and ANEG $(p<0,05)$.

In the analysis of $\mathrm{Mn}$, separated by exercise specialties, important changes can be found. Only AEG present higher $(p<0,001)$ concentrations than CG. Contrary, the other sport modalities present different Mn concentrations; both groups shown lower concentrations than CG, being the most significance $(p<0,001)$ the AE-ANEG group followed by ANEG $(p<0,01)$. Therefore, the highest concentrations are present in AEG, followed by CG, AE-ANEG and AEG.

$\mathrm{Ni}$ presented higher $(p<0,001)$ concentrations in all sportsmen in respect to control group. However, $\mathrm{Ni}$ highest concentrations were found in AEG $(p<0,001)$, followed by ANEG $(p<0,001)$ and AE-ANEG present the lowest $(p<0,01)$ concentrations.

Se presented lower serum concentrations in all sportsmen respect CG $(p<0,001)$. The lowest $(p<0,001)$ concentrations were founded in ANEG group, followed by AE-ANEG group $(p<0,01)$. The highest $(p<0,05)$ Se concentrations belonged to AEG.

\section{Discussion}

One of the main exposure sources to trace elements is diet [13]. In this survey, nutritional intake was analysed by recording each gram of each food ingested during the evaluation days. Once the total daily amounts of each

Table 5 Serum trace element concentrations of control group and high-level sportsmen

\begin{tabular}{lll}
\hline Element & $\begin{array}{l}\text { CG } \\
(n=31)\end{array}$ & $\begin{array}{l}\text { SPG } \\
(n=80)\end{array}$ \\
\hline $\mathrm{Cr}\left(\mu \mathrm{g} \cdot \mathrm{L}^{-1}\right)$ & $0.22 \pm 0.24$ & $1.92 \pm 3.13^{* * *}$ \\
$\mathrm{Cu}\left(\mu \mathrm{g} \cdot \mathrm{L}^{-1}\right)$ & $759.46 \pm 108.40$ & $784.63 \pm 143.03$ \\
$\mathrm{Mn}\left(\mu \mathrm{g} \cdot \mathrm{L}^{-1}\right)$ & $1.185 \pm 0.44$ & $1.63 \pm 1.46^{*}$ \\
$\mathrm{Ni}\left(\mu \mathrm{g} \cdot \mathrm{L}^{-1}\right)$ & $0.51 \pm 0.41$ & $1.93 \pm 2.22^{* * *}$ \\
$\mathrm{Se}\left(\mu \mathrm{g} \cdot \mathrm{L}^{-1}\right)$ & $102.37 \pm 12.99$ & $85.64 \pm 17.86^{* * *}$ \\
\hline
\end{tabular}

Student test $\left({ }^{*} p<0.05,{ }^{* *} p<0.01 ;{ }^{* *} p<0.001\right)$ differences between control group and sportsmen group aliments were summed, the amount of each specific mineral was obtained using several databases [13-15].

In this survey participated sedentary population (CG) as well as high level sportsmen of different modalities (Aerobic, Anaerobic and Mixed). A critical issue in this kind of surveys is a proper delineation of experimental groups in accordance with the predominant metabolic demands (aerobic, anaerobic or aerobic-anaerobic metabolisms), because each specific sport induces different biological adaptations according to the metabolisms developed in of each activity. $\mathrm{RER}_{\max }$ could be an interesting variable to differentiate groups due to the link between RER values and anaerobic $\mathrm{CO}_{2}$ production [10]. Data about RERs in Table 2 manifests proper differences among sports groups and was used as criteria to verify that sportsmen groups was accurately delineated.

Sportsmen have, in comparison to sedentary population, greater energetic demands, due to their physical training. This fact is reflected in the obtained results, being the caloric intake $(\mathrm{Kcal} / \mathrm{d})$ significantly higher $(p<$ 0.01 ) among sportsmen, but only in the AEG. Theoretically, sportsmen should present, due to an augmented food intake, greater mineral intake, but, contradictorily, the obtained results have shown similar mineral values. This fact was previously analysed in a review of Gupta and Gupta [17]. In this review, it was reported that although takin a balanced and varied diet there is a great percentage of possibilities to have a lack of some elements. The main reason of this fact is the chemical composition of grounds, poor in several minerals. This idea can explain why the sportsmen of this survey have similar nutritional intake of minerals in spite of ingest sensibly higher amounts of foods. Another possible explanation could be that athletes ingested low amounts of foods rich in the studied elements.

Despite similar nutritional intake of minerals. it can be observed significant differences in serum concentrations of essential trace metals between sportsmen and sedentary people. However, mineral seric values were within reference concentrations [18] with the exception of $\mathrm{Cr}$, which presented concentrations under normal values in 
Table 6 Serum trace elements concentrations of control group and sportsmen separated by metabolic specialties

\begin{tabular}{lllll}
\hline Element & GG & AEG & ANEG & AE-ANEG \\
& $(n=31)$ & $(n=28)$ & $(n=24)$ & $(n=28)$ \\
\hline $\mathrm{Cr}\left(\mu \mathrm{g} \cdot \mathrm{L}^{-1}\right)$ & $0.15 \pm 0.20$ & $1.43 \pm 4.10^{* * *}$ & $0.44 \pm 0.24^{* * *+\dagger}$ & $0.70 \pm 0.504^{* * *+++}$ \\
$\mathrm{Cu}\left(\mu \mathrm{g} \cdot \mathrm{L}^{-1}\right)$ & $750.46 \pm 113.47$ & $741.49 \pm 114.15$ & $767.66 \pm 74.83$ & $857.91 \pm 180.55^{* *++}$ \\
$\mathrm{Mn}\left(\mu \mathrm{g} \cdot \mathrm{L}^{-1}\right)$ & $1.10 \pm 0.41$ & $2.54 \pm 1.74^{* * *}$ & $0.81 \pm 0.24^{* *+\dagger}$ & $1.02 \pm 0.39^{* * *+++}$ \\
$\mathrm{Ni}\left(\mu \mathrm{g} \cdot \mathrm{L}^{-1}\right)$ & $0,47 \pm 0.43$ & $2.87 \pm 2.95^{* * *}$ & $1.11 \pm 0.35^{* * *+}$ & $1.00 \pm 0.69^{* *+\dagger}$ \\
$\mathrm{Se}\left(\mu \mathrm{g} \cdot \mathrm{L}^{-1}\right)$ & $102.87 \pm 13.80$ & $94.16 \pm 13.61^{*}$ & $79.17 \pm 11.48^{* * *+\dagger}$ & $84.01 \pm 23.43^{* \dagger}$ \\
\hline
\end{tabular}

Anova and Bonferroni tests. $\left.{ }^{*} p<0.05 ;{ }^{* *} p<0.01 ;{ }^{* * *} p<0.001\right)$ differences between control group and aerobic, anaerobic and aerobic-anaerobic groups; ( $+p<$ $0.05 ; \dagger+p<0.01 ;+\uparrow+p<0.001)$ differences between aerobic group and anaerobic and aerobic-anaerobic groups; $(\square p<0.05 ; \square \square p<0.01 ; \square \square \square<0.001)$ differences between anaerobic group and aerobic-anaerobic group

the CG. This fact could be due to a diminution in the intake, as Clarkson [19] indicated, fact that has not been reflected in the obtained results.

Seric Cr concentrations were higher $(p<0.001)$ in SPG in comparison to CG. Berger et al. [20], found in marathon runner's values of this element similar to the results obtained in this survey. However, they had not control group. They also reported high $\mathrm{Cr}$ concentrations before and after the race, being sensibly higher than in our sportsmen. Normal or sensibly augmented $\mathrm{Cr}$ values could be highly relevant to sportsmen because of the link of this element with insulin, a critical hormone for high level physical demands [1-3].

If sportsmen are classified by metabolic modalities and compared to the CG it can be observed that all sportsmen, independently of the nature of the exercise, presented greater $\mathrm{Cr}$ values than controls. The highest $\mathrm{Cr}$ values are reported in the AEG, followed by the AEANEG, and being the lowest in the ANEG. This fact could be linked to the insulin-related $\mathrm{Cr}$ role, being critical in aerobic modalities, where insulin regulates the substrates metabolism; in the other two modalities, this hormone takes a less important role. It is well known that the practice of physical exercise decreases the blood glucose and insulin levels. These effects may be observed even in only one exercise session and may last for several hours after the end of the effort. If regular practice of physical exercise is performed, a chronic blood glucose diminution may occur [21].

Long-term Cr supplementation effects have been studied involving long periods of time (12-24 weeks). It has been associated high daily doses of chromium $\left(400 \mu \mathrm{g} \cdot \mathrm{day}^{-1}\right)$ with significant reductions in body fat mass of 5\% [22-25]. This fact indicates that the effects of chromium on body re-composition may occur; however, these effects require high dosage, long supplementation, periods.

In the present survey, the highest $\mathrm{Cr}$ serum concentrations have been found in AEG, which is the group with the lowest body fat amounts. This fact can be mainly due to physical exercise by itself but, in all cases, is in accordance with the previous reports and it could strengthen the hypothesis of Rubin et al. [26], who indicated that body composition changes, body fat diminutions or free fat weight increments can be produced by physical exercise by itself or by the exercise-associated serum $\mathrm{Cr}$ increments.

In the case of $\mathrm{Cu}$, no differences were found between the SPG and the CG. However, if SPG participants are separated by metabolic modalities, serum $\mathrm{Cu}$ concentrations are significantly higher $(p<0.01)$ in the AE-ANEG in comparison to the CG and higher in the ANEG than in the AEG $(p<0.01)$. Cu has been previously studied in plasma of high level aerobic and anaerobic sportsmen compared to a control group (who performed moderate physical activities) [27]. The results of this previous research showed that anaerobic sportsmen had significantly higher concentrations than controls and aerobic sportsmen. The results obtained here are in accordance to this previous report, being the highest concentrations in football players who performed aerobic-anaerobic training programs. The $\mathrm{Cu}$ concentrations in the AEANEG concentrations were also higher $(p<0.01)$ than in the CG. The increase on these concentrations could be due to exercise-induced rhabdomyolysis, as consequence of daily training. When muscle tissues impact increases, as occur in high-intensity activities, this effect is augmented [28].

It could be stated that aerobic exercises develop more reductions in blood $\mathrm{Cu}$ levels among athletes [29]. Resina, Gatteschi, Rubenni, Giamberardino, and Imreh [30] found among soccer players lower serum ceruloplasmin levels and lower serum ceruloplasmin biological activity than in the control group. However, serum $\mathrm{Cu}$ levels were comparable in both groups. These results suggest that more attention should be focussed to serum $\mathrm{Cu}$ and ceruloplasmin among soccer players.

$\mathrm{Mn}$ is a compound of superoxide dismutase enzyme (Mn-SOD). Thereby, in several researches, it has been observed that physical exercise increases the Mn-SOD activity in the myocardium and in the mitochondria [31-33]. This is a critical fact among sportsmen because 
Mn-SOD is a mitochondrial antioxidant enzyme which neutralize superoxide radicals formed during the exercise. Furthermore, Mn develops important functions in gluconeogenesis and urea formation processes as an active compound of several involved enzymes. These processes are essential, becoming critical in aerobic sportsmen [31, 33]. Sánchez, López-Jurado, Aranda, and Llopis [34] in a work developed in the south of Spain, studied among sedentary and physically active populations $\mathrm{Mn}$ blood concentrations. These authors found the highest concentrations in active participants. The higher Mn concentrations in sportsmen would be linked to an increased organic utilization of this mineral in the mitochondrial Mn-SOD production processes, among others [34]. Higher basal blood Mn concentrations in aerobic athletes in comparison with other metabolic sportsmen could be linked to a probably lower iron (Fe) levels, fact that is common in long distance sportsmen, as a consequence of the impact of Fe body levels in Mn metabolism [35, 36]. In this sense, it has been observed increased blood Mn levels in Fe deficitary cases [37, 38]. The fact that the AEG had the higher concentrations, followed with the AE-ANEG and the ANEG in our study, verifies and reinforces the previous reports.

$\mathrm{Ni}$ controls tissular levels of phospholipids, triglycerides, urea, glucose, glycogen and ATP $[4,5]$. Due to these roles is critical among sportsmen to maintain high organic concentrations of this mineral. Berger et al. [20] found in marathon runners similar blood $\mathrm{Ni}$ levels that in the present survey. However, they had no control group.

The highest $(p<0.001) \mathrm{Ni}$ concentrations in this survey have been reported in sportsmen. This fact could be linked to their high training volume as well as to the higher daily quantities of metabolic reactions needed to maintain high performance levels, specially among aerobic sportsmen. As previously indicated, it is known that $\mathrm{Ni}$ regulates tissular concentrations of substrates and metabolites, which are significantly altered during longduration trainings and competitions. The obtained data reinforces this idea, being in aerobic participants the highest concentrations, followed by anaerobic and aerobic-anaerobic exercises $(p<0.001)$.

About the role of Se in sportsmen, it is known that physical activity generates an increase in free radicals of oxygen production, being this the fact which conduces sportsmen to improve their antioxidant system, as adaptive mechanism. A specific adaptive change is the behaviour of the enzyme GSH-Px, a Se protein [39].

The obtained results manifest lower Se concentrations in all sportsmen in comparison to CG. Sánchez et al. [34] also found lower Se values in active population in comparison to sedentary people. Se intake from food was not enough to maintain the constant levels of blood
Se during training. Because the estimated intake of $48 \mu \mathrm{g} \cdot$ day-1 was nevertheless higher than the lower recommended level (30 $\mu \mathrm{g}$.day-1), it should be considered that in sportsmen population the recommendation should be increased [40]. The main reason of this affirmation is that Se requirements are increased among athletes [41].

This could be an important cause of the low Se concentrations found in our sportsmen. An augmented production of GSH-Px and a major synthesis of other Seproteins could be a reasonably justification of the lower Se values among sportsmen.

In the present study the lowest concentration was found in the ANEG $(p<0.001)$ followed by the AEANEG and the AEG. Pograjc et al. [40] found decreased Se plasma levels during training of intensive physical activity. This fact suggests a slowly biologically active decreasing Se pool. The results of the study of Akil et al. [39] indicated that decreased liver glycogen levels in acute swimming exercise can be restored by selenium administration. It is possible, so, that the cause of the lowest Se concentrations in the ANEG and the AEANEG was a greater and more rapid replacement of muscular glycogen necessary for a high performance in these modalities. The results of the study of Akil et al. [39] indicate that the increase in free radical production and lactate levels due to acute swimming exercise in rats might be offset by selenium supplementation. Selenium supplementation may be important in that it supports the antioxidant system in physical activity. Physical activities which produce lactate and high amounts of free radicals are anaerobic, so, as the previous work indicated, anaerobic sportsmen would need more Se quantities to overcome the exercise-induced metabolic situations as well as to avoid oxidative damage. This could explain the obtained data.

A nutritional plan rich in Se containing foods may be beneficial for both athletes who exercise regularly and in patients with increasing oxidative stress [42].

Finally, regarding the limitations of this survey it has to be mentioned that to know the exact metabolic behaviour of each element, more matrixes have to be analysed, like urine, plasma, or sweat. The inclusion of these other matrixes could inform about the degree of elimination and redistribution of each element. In further surveys, multi-matrix studies should be carried out tin order to deep in the knowledge of the exact effect of diet and exercise in the organic trace elements values.

\section{Conclusions}

This research manifests that essential mineral elements play a critical role in the metabolism of continuous physical practice cases. As consequence of specific physical training, sportsmen serum concentrations suffer different 
changes related to the nature of the efforts and training modality practised.

In some cases, the upper demands induced by highlevel training make necessary to maintain high serum bioavailability of these elements to ensure quick responses to the exercise-induced cellular changes as well as to prevent considerable losses which could reduce physical performance.

So, these findings should be considered to develop specific supplementation processes, when it be necessary. This plan seems critically important in the case of Se. Also, research/evaluations of this elements are essential for trainers and high-level sportsmen, to prevent performance injuries during the season and to ensure an optimum physiologic status.

\section{Acknowledgments}

The authors gratefully acknowledge the collaboration of SAIUex.

The research was conducted in the laboratory of Physiology of the School of Sport Sciences (University of Extremadura).

\section{Funding}

No fundings.

\section{Availability of data and materials}

All data generated or analysed during this study are included in this published article.

\section{Authors' contributions}

MM designed the study; data were collected and analyzed by MM, FL, F-JG and JA; DM, M-CR and IB undertook data interpretation and manuscript preparation. All authors approved the final version of the paper.

\section{Ethics approval and consent to participate}

This research was carried out under the Helsinki Declaration ethic guidelines, updated at the World Medical Assembly in Seoul in 2008, for research with human subjects. All the participants were informed about the purpose of the study and gave their voluntary signed informed consent.

\section{Consent for publication}

Not applicable.

\section{Competing interests}

The authors declare that they have no competing interests.

\section{Publisher's Note}

Springer Nature remains neutral with regard to jurisdictional claims in published maps and institutional affiliations.

\section{Author details \\ 'Department of Physiology, School of Sport Sciences, University of Extremadura, University Avenue, 10003 Cáceres, Spain. ${ }^{2}$ Department of Medical-Surgical Therapeutics, School of Medicine, University of Extremadura, Elvas Avenue, 06071 Badajoz, Spain. ${ }^{3}$ Department of Sport Sciences, School of Sport Sciences, Pontifical University of Salamanca, Henry Collet Street, 53, 37007 Salamanca, Spain. ${ }^{4}$ Department of Physical Education and Sport, School of Sport Sciences, University of Extremadura, University Avenue, 10003 Cáceres, Spain.}

Received: 18 July 2017 Accepted: 9 February 2018 Published online: 13 February 2018

\section{References}

1. Hernández M, Sastre A. In: Díaz de Santos E, editor. Tratado de nutrición; 1999.
2. Mertz W. Chromium research from a distance: from 1959 to 1980. J Am Coll Nutr. 1998a;17(6):544-7.

3. Mertz W. Interaction of chromium with insulin: a progress report. NutrRev. 1998b;56:174-7.

4. Cartañà J, Arola L. Nickel-induced hyperglycaemia: the role of insulin and glucagon. Toxicology. 1992;71(1-2):181-92.

5. M'Bemba-Meka P, Lemieux N, Chakrabarti S. Nickel compound-induced DNA single-strand breaks in chromosomal and nuclear chromatin in human blood lymphocytes in vitro: role of oxidative stress and intracellular calcium. Mutat Res. 2005;586(2,3):124-37.

6. Mena P, Maynar M, Gutierrez JM, Maynar J, Timon J, Campillo JE. Erythrocyte free radical scavenger enzymes in bicycle professional racers. Adaptation to training. Int J Sports Med. 1991;12(6):563-6. https://doi.org/10.1055/s-2007-1024734.

7. Clarkson PM, Haymes EM. Trace mineral requirements for athletes. Int J Sport Nutr. 1994;4(2):104-19.

8. Maynar M, Llerena F, Grijota FJ, Alves J, Robles MC, Bartolomé I, Muñoz D. Serum concentration of several trace metals and physical training. J Int Soc Sports Nutr. 2017:14(1):19.

9. Niemelä K, Palatsi I, Takkunen J. The oxygen uptake - work-output relationship of runners during graded cycling exercise: sprinters vs endurance runners. Br J Sports Med. 1980;14:204-9.

10. Goedecke JH, Gibson ASC, Grobler L, Collins M, Noakes TD, Lambert EV. Determinants of the variability in respiratory exchange ratio at rest and during exercise in trained athletes. Am J Physiol Endocrinol Metab. 2000; 279(6):E1325-34.

11. Holloway, S. M., Bliss, M. V., \& Hearon, C. M. (2017). Acute responses to high intensity interval exercise and moderate aerobic exercise on anaerobically and aerobically trained athletes. Paper presented at the International Journal of Exercise Science: Conference Proceedings.

12. Hoff J, Støren $\varnothing$, Finstad A, Wang E, Helgerud J. Increased blood lactate level deteriorates running economy in world class endurance athletes. $J$ Strength Cond Res. 2016;30(5):1373-8.

13. Kabata-Pendias A, Mukherjee AB. Trace elements from soil to human. Heidelberg: Springer; 2007.

14. Reilly C. The nutritional trace metals. Oxford: Blackwell Publishing; 2004

15. Tuni, O. M., Carbajal, Á., Forneiro, L. C., \& Vives, C. C. (2008). Tablas de composición de alimentos.

16. Sarmiento-Gonzalez A, Marchante-Gayon JM, Tejerina-Lobo JM, Paz-Jimenez J, Sanz-Medel A. ICP-MS multielemental determination of metals potentially released from dental implants and articular prostheses in human biological fluids. Anal Bioanal Chem. 2005;382(4):1001-9. https://doi.org/10.1007/ s00216-005-3165-9.

17. Gupta U, Gupta S. Sources and deficiency diseases of mineral nutrients in human health and nutrition: a review. Pedosphere. 2014;24(1):13-38.

18. Lu Y, Ahmed S, Harari F, Vahter M. Impact of Ficoll density gradient centrifugation on major and trace element concentrations in erythrocytes and blood plasma. J Trace Elem Med Biol. 2015;29:249-54.

19. Clarkson PM. Effects of exercise on chromium levels. Sports Med. 1997;23(6): 341-9.

20. Berger CE, Kröner A, Kluger R, Baron R, Steffan I, Engel A. Effects of marathon running on the trace minerals chromium, cobalt, nickel, and molybdenum. J Trace Trace Elem Exp Med. 2002;15(4):201-9.

21. Goodyear P, Laurie J, Kahn M, Barbara B. Exercise, glucose transport, and insulin sensitivity. Annu Rev Med. 1998:49(1):235-61.

22. Anderson RA. Effects of chromium on body composition and weight loss. Nutr Rev. 1998;56(9):266-70.

23. Gomes M, Tirapegui J. Cromo: novo nutriente ergogênico utilizado na atividade física. Nutr Pauta. 2004:64:23-33.

24. Kreider RB. Dietary supplements and the promotion of muscle growth with resistance exercise. Sports Med. 1999;27(2):97-110.

25. Trent L, Thieding-Cancel D. Effects of chromium picolinate on body composition. Journal of sports medicine and physical fitness. 1995;35(4):273-80.

26. Rubin MA, Miller JP, Ryan AS, Treuth MS, Patterson KY, Pratley RE, Anderson RA. Acute and chronic resistive exercise increase urinary chromium excretion in men as measured with an enriched chromium stable isotope. J Nutr. 1998;128(1):73-8.

27. Rodríguez-Tuya I, Pinilla E, Maynar M, García-Moncó RM, Sánchez A. Evaluation of the influence of physical activity on the plasma concentrations of several trace metals. Eur J Appl Physiol Occup Physiol. 1996;73(3):299-303. 
28. Granell J. Zinc and copper changes in serum and urine after aerobic endurance and muscular strength exercise. J Sport Med Phys Fitness. 2014; 54(2):232-7.

29. Savas S. Effect of maximal aerobic and anaerobic exercise on blood zinc and copper levels of male athletes. Asian J Chem. 2009;21(5):3962.

30. Resina A, Gatteschi L, Rubenni MG, Giamberardino MA, Imreh F. Comparison of some serum copper parameters in trained professional soccer players and control subjects. J Sport Med Phys Fitness. 1991;31:413-6.

31. Bicer M, Gunay M, Baltaci AK, Uney K, Mogulkoc R, Akil M. Effect of zinc supplementation on lipid peroxidation and lactate levels in rats with diabetes induced by streptozotocin and subjected to acute swimming exercise. Bratisl Lek Listy. 2012;113(4):199-205.

32. De Lisio M, Kaczor JJ, Phan N, Tarnopolsky MA, Boreham DR, Parise G. Exercise training enhances the skeletal muscle response to radiationinduced oxidative stress. Muscle Nerve. 2011;43(1):58-64. https://doi.org/10. 1002/mus.21797

33. Lee $Y$, Min K, Talbert EE, Kavazis AN, Smuder AJ, Willis WT, Powers SK. Exercise protects cardiac mitochondria against ischemia-reperfusion injury. Med Sci Sports Exerc. 2012;44(3):397-405. https://doi.org/10.1249/MSS Ob013e318231c037.

34. Sánchez C, López-Jurado M, Aranda P, Llopis J. Plasma levels of copper, manganese and selenium in an adult population in southern Spain: influence of age, obesity and lifestyle factors. Sci Total Environ. 2010; 408(5):1014-20.

35. Garrick M, Kuo H, Vargas F, Singleton S, Zhao L, Smith J. Comparison of mammalian cell lines expressing distinct isoforms of divalent metal transporter 1 in a tetracycline-regulated fashion. Biochem J. 2006;398: 539-46.

36. Momãiloviõ B. Manganese whole body retention and the gastrointestinal transit time of the women in their reproductive age are intensively related to the ferritin status, vol. 2. Jena: 22 Workshop, Macro and Trace Elements; 2004. p. 1715-22.

37. Kim Y, Lee B-K. Iron deficiency increases blood manganese level in the Korean general population according to KNHANES 2008. Neurotoxicology. 2011:32(2):247-54

38. Meltzer H, Brantsaeter A, Borch-lohnsen B, Ellingsen D, Alexander J, Thomassen $Y$. Low iron stores are related to higher blood concentrations of manganese, cobalt and cadmium in non-smoking, Norwegian women in the HUNT 2 study. Environ Res. 2010;110:497-504.

39. Akil M, Gurbuz U, Bicer M, Sivirikaya A, Mogulkoc R, Baltaci AK. Effect of selenium supplementation on lipid peroxidation, antioxidant enzymes, and lactate levels in rats immediately after acute swimming exercise. Biol Trace Elem Res. 2011;142(3):651-9.

40. Pograjc L, Stibilj V, Falnoga I. Impact of intensive physical activity on selenium status. Biol Trace Elem Res. 2012;145(3):291-9.

41. Margaritis I, Rousseau AS, Hininger I, Palazzetti S, Arnaud J, Roussel AM. Increase in selenium requirements with physical activity loads in welltrained athletes is not linear. Biofactors. 2005;23(1):45-55.

42. Emre MH, Düzova H, Sancak B, Polat A, Erdoğan H, Yologlu S. Serum selenium response to maximal anaerobic exercise among sportsmen trained at various levels. J Trace Elem Exp Med. 2004;17(2):93-100.

\section{Submit your next manuscript to BioMed Central and we will help you at every step:}

- We accept pre-submission inquiries

- Our selector tool helps you to find the most relevant journal

- We provide round the clock customer support

- Convenient online submission

- Thorough peer review

- Inclusion in PubMed and all major indexing services

- Maximum visibility for your research

Submit your manuscript at www.biomedcentral.com/submit
Biomed Central 